\title{
Nerve Growth Factor Stimulates Glioblastoma Proliferation through Notch1 Receptor Signaling
}

\author{
Jun Chul Park, M.D., In Bok Chang, M.D., Ph.D., ${ }^{1}$ Jun Hyong Ahn, M.D., Ji Hee Kim, M.D., Joon Ho Song, M.D., Ph.D., \\ Seung Myung Moon, M.D., Ph.D., ${ }^{2}$ Young-Han Park, M.D., Ph.D. ${ }^{3}$ \\ Department of Neurosurgery, Hallym University Sacred Heart Hospital, Anyang, Korea \\ Department of Neurosurgery, ${ }^{2}$ Dongtan Sacred Heart Hospital, Hwaseong, Korea \\ Department of Obstetrics and Gynecology, ${ }^{3}$ Hallym University Sacred Heart Hospital, Anyang, Korea
}

Objective : Notch receptors are heterodimeric transmembrane proteins that regulate cell fate, such as differentiation, proliferation, and apoptosis. Dysregulated Notch pathway signaling has been observed in glioblastomas, as well as in other human malignancies. Nerve growth factor (NGF) is essential for cell growth and differentiation in the nervous system. Recent reports suggest that NGF stimulates glioblastoma proliferation. However, the relationship between NGF and Notch1 in glioblastomas remains unknown. Therefore, we investigated expression of Notch1 in a glioblastoma cell line (U87-MG), and examined the relationship between NGF and Notch1 signaling.

Methods : We evaluated expression of Notch1 in human glioblastomas and normal brain tissues by immunohistochemical staining. The effect of NGF on glioblastoma cell line (U87-MG) was evaluated by 3-(4, 5-dimethylthiazol-2-yl)-2, 5-diphenyltetrazolium bromide (MTT) assay. To evaluate the relationship between NGF and Notch1 signaling, Notch1 and Hes1 expression were evaluated by reverse transcription polymerase chain reaction (RT-PCR) and Western blot analysis, respectively. To confirm the effects of NGF on Notch1 signaling, Notch1 and Hes1 small interfering RNAs (siRNAs) were used.

Results : In immunohistochemistry, Notch1 expression was higher in glioblastoma than in normal brain tissue. MTT assay showed that NGF stimulates U87-MG cells in a dose-dependent manner. RT-PCR and Western blot analysis demonstrated that Notch1 and Hes1 expression were increased by NGF in a dose-dependent manner. After transfection with Notch1 and Hes1 siRNAs, there was no significant difference between controls and 100 nM NGF- $\beta$, which means that U87-MG cell proliferation was suppressed by Notch1 and Hes1 siRNAs.

Conclusion : These results indicate that NGF stimulates glioblastoma cell proliferation via Notch1 signaling through Hes 1.

Key Words : Glioblastoma · Nerve growth factor · Notch1.

\section{INTRODUCTION}

Glioblastoma (World Health Organization grade IV) is the most common type of glioma and the most common malignant primary brain tumor in adults. Glioblastomas usually develop in the cerebral hemisphere as a solitary tumor and may

- Received : July 24, 2017 •Revised : October 16, 2017 •Accepted : January 9, 2018

- Address for reprints : In Bok Chang, M.D., Ph.D.

Department of Neurosurgery, Hallym University Sacred Heart Hospital, 22 Gwanpyeong-ro 170beon-gil, Dongan-gu, Anyang 14068, Korea Tel : +82-31-380-3771, Fax : +82-31-380-3748, E-mail : nscib71@gmail.com

This is an Open Access article distributed under the terms of the Creative Commons Attribution Non-Commercial License (http://creativecommons.org/licenses/by-nc/4.0) which permits unrestricted non-commercial use, distribution, and reproduction in any medium, provided the original work is properly cited. 
also occur in the cerebellum and the spinal cord. Even though the current standard of care includes maximal surgical resection, adjuvant chemotherapy and radiotherapy, the prognosis of glioblastoma is poor.

Notch signaling, a fundamental signaling system, regulates cell proliferation and differentiation through lateral inhibition and has been known to be involved with tumorigenesis ${ }^{3,12}$. Notch receptors are heterodimeric transmembrane proteins that regulate cell fate, such as differentiation, proliferation, and apoptosis in numerous tissues ${ }^{39)}$. In mammals, there are four types of Notch receptors (Notch1, Notch2, Notch3, and Notch4) and five classic ligands (Delta-like1, Delta-like3, Delta-like4, Jagged1, and Jagged2) ${ }^{1}$. Dysregulated Notch pathway signaling has been identified in brain tumors, as well as in many other tumors including hematologic malignancies, cervical, lung, pancreatic, breast cancer, hepatocellular carcinomas, and in ovarian $^{2,4,7,17,19,22,23,26)}$. Notch expression and the correlation between tumor grades differ between previous reports and these differences have not been fully clarified. Of Notch receptors, Notchl has been reported to be oncogenic and show positive correlation with glioma progression ${ }^{20,38)}$. However, the tumor suppressive role of Notch 1 has been identified in other reports $^{8,27)}$.

Nerve growth factor (NGF) is a member of the neurotrophin family and is essential for cell growth and differentiation in both the peripheral and central nervous system ${ }^{377}$. NGF interacts with two receptors, such as TrkA and $\mathrm{p} 75^{\mathrm{NTR}}$, which have also been identified in glioblastoma cell lines ${ }^{6,10,25)}$. NGF has been described as an inhibitor of tumor cell different proliferation, or mitogenesis ${ }^{11,30-32)}$. Recent reports suggest that NGF stimulates glioblastoma proliferation ${ }^{10,18,25,33)}$.

Although there is much evidence that Notch signaling pathway is involved in glioblastoma pathogenesis, the frequency of specific Notch receptor expression, the mechanisms underlying Notch activation, and whether NGF is involved with Notchl signaling are still unknown. Therefore, we investigated expression of Notch1 in a glioblastoma cell line (U87-MG), and examined the relationship between NGF and Notch1 signaling.

\section{MATERIALS AND METHODS}

\section{Human tissue samples}

Human glioblastoma and normal brain tissues, including surgically resected tissue adjacent to infiltrating glioblastoma or traumatic brain tissue, were obtained from our hospital. Normal brain tissues were obtained at the area that has no visible tumor cells during tissue analyses by pathologist and during surgery for traumatic brain injury. This study was approved by the Hallym University Institutional Review Board (2016-I160).

\section{Immunohistochemical staining}

Paraffin-embedded tissue sections were subjected to immunostaining using rabbit polyclonal to Notch1 antibodies (ab27526, Abcam, Cambridge, UK) at a 1:50 dilution. Primary antibody was diluted in phosphate-buffered saline with 5\% normal blocking serum. Rabbit IgG antibody (PK-6101, Vector laboratories, Burlingame, CA, USA) was used as the secondary antibody. Immunohistochemistry was performed as described elsewhere. A streptavidin-biotin-peroxidase complex technique was used to reveal antibody-antigen reactions. Staining with 3,3'-diaminobenzidine was performed under a microscope for 1 minute (SK-4100, Vector laboratories). Slides were counterstained with hematoxylin (H-3401, Vector laboratories). After immunohistochemical controls were performed, normal brain tissue was used as a negative control and included omission of the primary antibody. The evaluation of immunohistochemical staining for Notch1 was performed by analyzing 10 different tumor fields and the mean percentage of tumor cells with positive staining was scored. For the qualitative assessment of immunohistochemical staining, the staining was divided as positive and negative.

For the quantitative assessment, staining has semiquantitatively been scored as : 1) negative - less than $10 \%$ of positive cells, 2) positive - immunoreactivity is more that $10 \%$ positive cancer cells. We did not count the percentage of positive cell numbers, but estimated the ratio in areas of the cancer cells.

\section{Cell culture and cell proliferation assay}

The U87-MG cells were cultured in minimum essential medium containing $10 \%$ fetal bovine serum, L-Glutamine (2 $\mathrm{mM}$ ) and an antibiotic combination of $0.1 \mathrm{mg} / \mathrm{mL}$ streptomycin and $100 \mathrm{unit} / \mathrm{mL}$ penicillin (Gibco, Grand Island, NY, USA). The cells were incubated at $37^{\circ} \mathrm{C}$ in a humidified air atmosphere containing $5 \% \mathrm{CO}_{2}$. Cells were placed in a 96-well culture plate at $1 \times 10^{4}$ cells/well in $200 \mu \mathrm{L}$ culture medium. After 24 hours incubation at $37^{\circ} \mathrm{C}$, cells were treated for 48 hours with drugs (human NGF- $\beta$ ) (N1408, Sigma-Aldrich, St. Louis, MO, 
USA) and Notch1 small interfering RNA (siRNA) (HSS107248, Invitrogen, Carlsbad, CA, USA). Briefly, the culture medium was replaced with $200 \mu \mathrm{L}$ culture medium containing $0.5 \mathrm{mg} / \mathrm{mL}$ 3-(4, 5-dimethylthiazol-2-yl)-2, 5-diphenyltetrazolium bromide (MTT) (M5655, Sigma-Aldrich) and incubated for 2 hours. After 2 hours, the supernatant was removed and $200 \mu \mathrm{L}$ dimethyl sulfoxide was added to dissolve the formazan precimpitate at $37^{\circ} \mathrm{C}$. After 30 minutes, absorbance was measured at $570 \mathrm{~nm}$ with an automated microplate reader (Multiskan GO, Thermo Fisher Scientific, Finland). All experiments were repeated at least eight times.

\section{Western blotting of Notch1 and Hes1}

U87-MG cells were lysed in radioimmunoprecipitation assay buffer $(150 \mathrm{mM} \mathrm{NaCl}, 1.0 \%$ Nonidet P-40, 0.5\% sodium desoxycholate, $0.1 \%$ sodium dodecyl sulfate, $0.5 \mathrm{mM}$ Tris, $\mathrm{pH}$ 8.0) on ice for 30 minutes, followed by centrifugation for 20 minutes at $4^{\circ} \mathrm{C}$. Quantification was done by Bradford assay (Bio-Rad, Glattbrugg, Switzerland). In all, 50 microgram total cellular protein per lane was size fractionated on a 7\% Tris-acetate gel (Invitrogen, Carlsbad, CA, USA) for Notch1 detection and transferred onto nitrocellulose (Schleicher and Schuell, Kassel, Germany). Equal loading and transfer efficiency was visually checked by Ponceau staining. Membranes were blocked overnight at $4^{\circ} \mathrm{C}$ temperature with $5 \%$ weight/volume (w/v) nonfat dry milk/Tris-buffered saline and Tween-20 (0.05\% w/v). Membranes were incubated with rabbit polyclonal anti-Notch1 antibodies (H-131, Santa Cruz Biotechnology, Inc., Santa Cruz, CA, USA) for the detection of the extracellular domain of Notch1. Experiments were repeated more than three times. The densities of the bands were measured by the software program (Image 1.47v, NIH, Bethesda, MD, USA) and the density values were compared statistically.

\section{Reverse transcriptionPCR (RT-PCR)}

Total RNA was extracted using TRIzol reagent (Invitrogen, Carlsbad, CA, USA) and CDNA was synthesized using amfiRivert cDNA Synthesis Platinum Master Mix (R5600, GenDEPOT, Barker, TX, USA) according to the manufacturer's instructions. Subsequently, cDNA was used for each PCR reaction with each primer pair. PCR products were separated on a 1 percent agarose gel containing ethidium bromide. Experiments were repeated more than five times. The densities of the bands were measured by the program (ImageJ $1.47 \mathrm{v}, \mathrm{NIH}$ ). The densi- ty values were analyzed statistically. Primers were as follows :

1) The Notchl primer; sense : 5'AGATCAACCTGGATGACTGTGCCA-3', antisense : 5'ACACGTAGCCACTGGTCATGTCTT-3'.

2) The glyceraldehyde-3-phosphate dehydrogenase (GAPDH) primers; sense : 5-GCTCTCCAGAACATCATCCCTGCC-3; antisense : 5-CGTTGTCATACCAGGAAATGAGCTT-3.

3) The Hesl primer; sense : 5'-AGATCAACCTGGATGACTGTGCCA-3', antisense : 5'ACACGTAGCCACTGGTCATGTCTT-3'.

\section{Immunofluorescence staining}

U87-MG cells were plated onto glass coverslips in 6-well culture dishes (100000 cells/2 mL medium/dish). After 24 hours incubation at $37^{\circ} \mathrm{C}$, the cells were treated for 48 hours with drugs (NGF- $\beta$ ). The cells were rinsed with phosphate-buffered saline (PBS) and fixed in 4\% formaldehyde in PBS for 10 minutes at room temperature, the fixed cells were incubated in $5 \%$ bovine serum albumin (BSA) in PBS for 2 hours. Cover slips were subsequently incubated 2 hours at room temperature with rabbit polyclonal antibodies against Notch1 (Abcam) (1:200 dilution). After washing, the slides were incubated in the dark at room temperature for 1 hour with fluorescein isothiocyanate (FITC)-labeled goat anti-rabbit IgG secondary antibodies (Santa Cruz) (1:200 dilution). Slides were mounted with Fluorescent mounting medium (S3023, Dako Cytomation, Carpinteria, CA, USA) and immunofluorescence staining images were acquired using a laser-scanning confocal inverted microscope (LSM700, Carl Zeiss, Jena, Germany).

\section{Statistical analysis}

Notchl and Hesl expression and clinico-pathological features were analyzed by paired t-test. $p$-values lower than 0.05 were accepted as statistically significant.

\section{RESULTS}

Presence of Notch1 in primary human glioblastoma

Immunohistochemistry was used to determine whether Notch1 expression is different in glioblastoma than in normal brain tissue. Notchl expression was evaluated by immunohistochemistry in 10 human glioblastoma tissues and in six normal brain tissues, including surgically resected tissue adjacent 
to infiltrating glioblastoma or traumatic brain tissue. Based on quantitative scoring of Notchl staining, a strong positive was identified in six cases (80\%) and moderately positive in four cases. There was no significant staining in six normal brain tissues, suggesting no immunoreactivity of Notch1 in normal brain tissue (Fig. 1).

\section{Nerve growth factor and U87-MG proliferation}

The authors evaluated the effect of NGF- $\beta$ in U87-MG cell line. After treatment of U87-MG cell lines with $0.1 \mathrm{nM}, 1 \mathrm{nM}$, $10 \mathrm{nM}, 50 \mathrm{nM}$, and $100 \mathrm{nM}$ NGF- $\beta$, cell proliferation was measured by MTT assay. The mean values of the MTT assays were $1.430,1.468,1.512,1.564$, and 1.625 in the NGF-treated cell lines, respectively, and 1.380 in the non-NGF treated cell line $(p=0.0054$, $0.0005,0.0001,0.0001$, and 0.0001) (Fig. 2). The findings suggested that NGF stimulates U87-MG cell line in a dose-dependent manner.

\section{Nerve growth factor induced expression of Notch1 and Hes1}

After observing that NGF stimulates proliferation of the U87MG cell line, Notch1 and Hesl expression were evaluated by RTPCR and Western blot analysis, respectively, to evaluate the relationship between NGF and Notch1 signaling. In controls ( 0 nM NGF- $\beta$ ), the mean density of Notch1 was 100 . The mean density of Notch1 in the RT-PCR was 143.02, 189.37, and 243.63 in $100 \mathrm{nM}, 200 \mathrm{nM}$, and $500 \mathrm{nM}$ NGF- $\beta$, respectively (Fig. 3A and B). There was a statistically significance at $500 \mathrm{nM}(p=0.044)$, but no statistically significance at $100 \mathrm{nM}$ or $200 \mathrm{nM}(p=0.054$, 0.054 , respectively). The mean density of Notch1 in the Western blot analysis was 114.81, 116.05, and 137.93 in $100 \mathrm{nM}, 200$ $\mathrm{nM}$, and $500 \mathrm{nM}$ NGF- $\beta$, respectively (Fig. 3C and D). There was a statistically significance at $500 \mathrm{nM}(p=0.037)$, but no sta- tistically significance at $100 \mathrm{nM}$ or $200 \mathrm{nM}(p=0.059,0.102$, respectively). Hes1 expression was then evaluated. The mean density of Hes1 was 100 in controls (0 nM NGF- $\beta$ ). The mean density of Hesl in the RT-PCR was 130.07 in 100 nM NGF- $\beta$, 136.92 in $200 \mathrm{nM}$ NGF- $\beta$, and 146.67 in $500 \mathrm{nM} \mathrm{NGF-} \beta$ ( $p=0.271,0.297$, and 0.020 , respectively) (Fig. $4 \mathrm{~A}$ and B). The mean density of Hesl in the Western blot analysis was 124.45 in $100 \mathrm{nM}$ NGF- $\beta$, 125.28 in $200 \mathrm{nM}$ NGF- $\beta$, and 142.03 in $500 \mathrm{nM}$ NGF- $\beta$ ( $p=0.109,0.073$, and 0.037 , respectively) (Fig. 4C and D). These findings show that NGF has a dose-dependent effect on Notch1 and Hes1 expression in U87-MG cell line.

\section{Notch1 gene suppression by siRNA removes the NGF effect}

To confirm the effects of NGF on Notch1 signaling, siRNAs targeting Notchl and Hesl were used. The efficacy of siRNA for

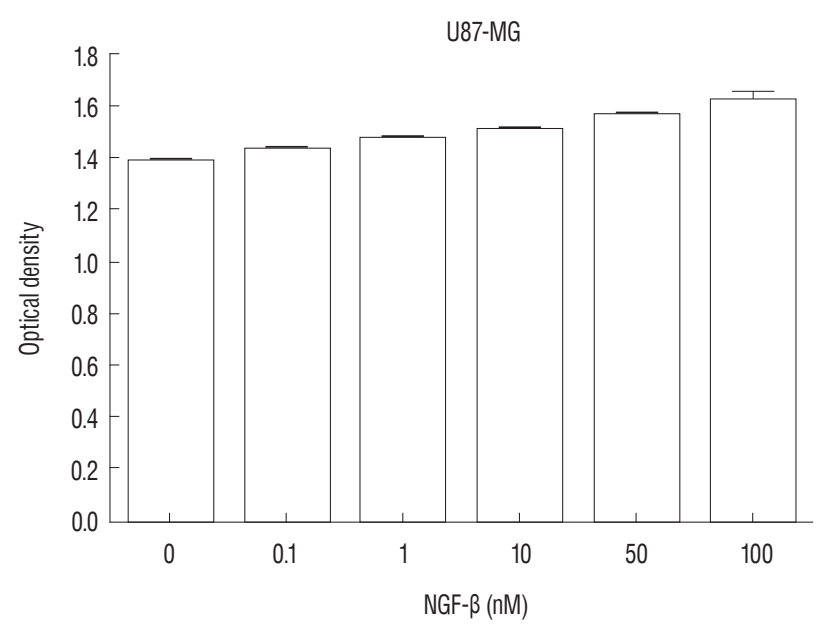

Fig. 2. 3-(4, 5-dimethylthiazol-2-yl)-2, 5-diphenyltetrazolium bromide (MTT) assay shows that nerve growth factor (NGF) stimulates U87-MG cell proliferation in a dose-dependent manner $(p=0.005)$.
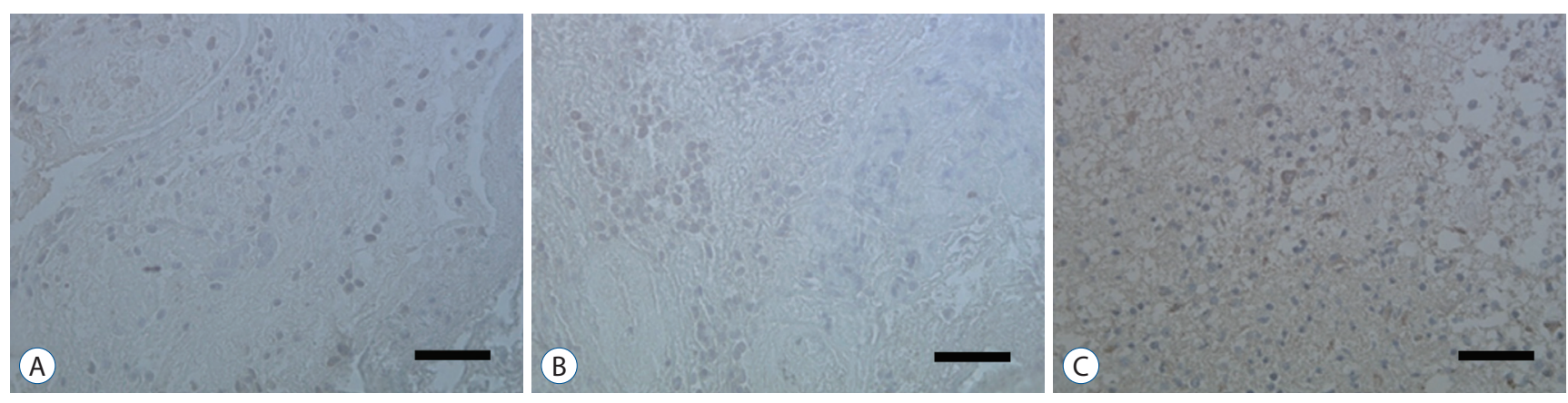

Fig. 1. Normal brain tissue (A) and negative control (B) show no staining, but human glioblastoma tissue (C) shows brown colored changes in the nucleus and cytoplasm by the streptavidin-biotin-peroxidase complex technique. Scale bar $=200 \mu \mathrm{m}$. 


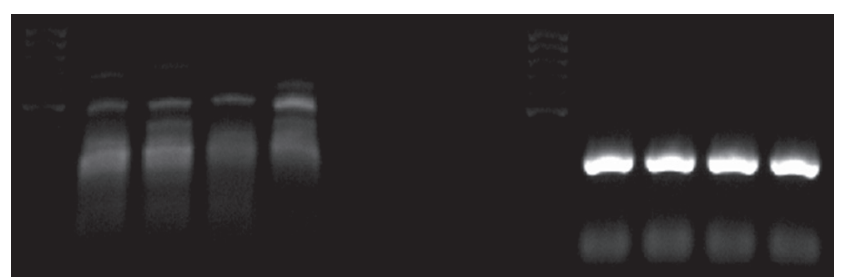

(A) Notch1

GAPDH

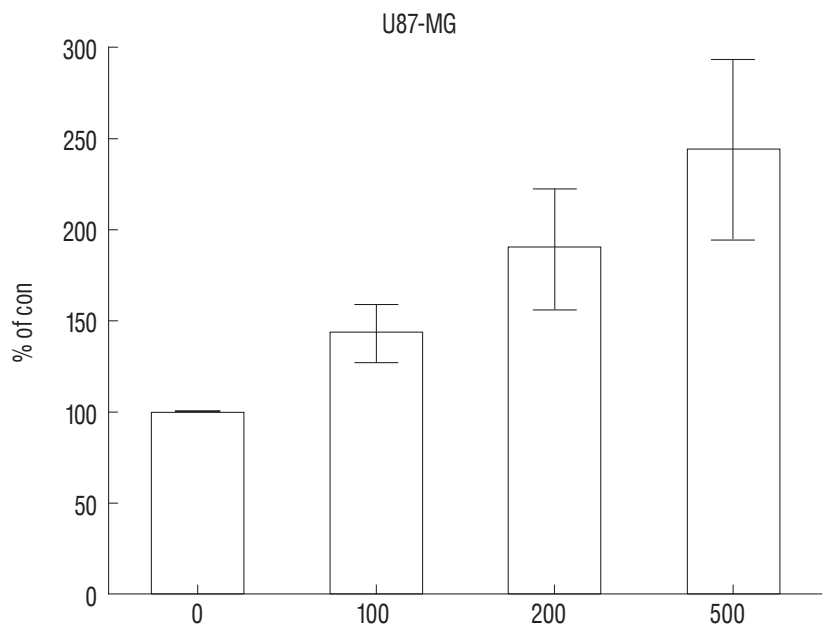

(B)

NGF- $\beta$ (nM)

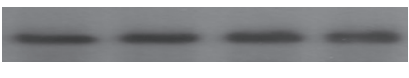

(C)

Notch1

$\beta$-actin

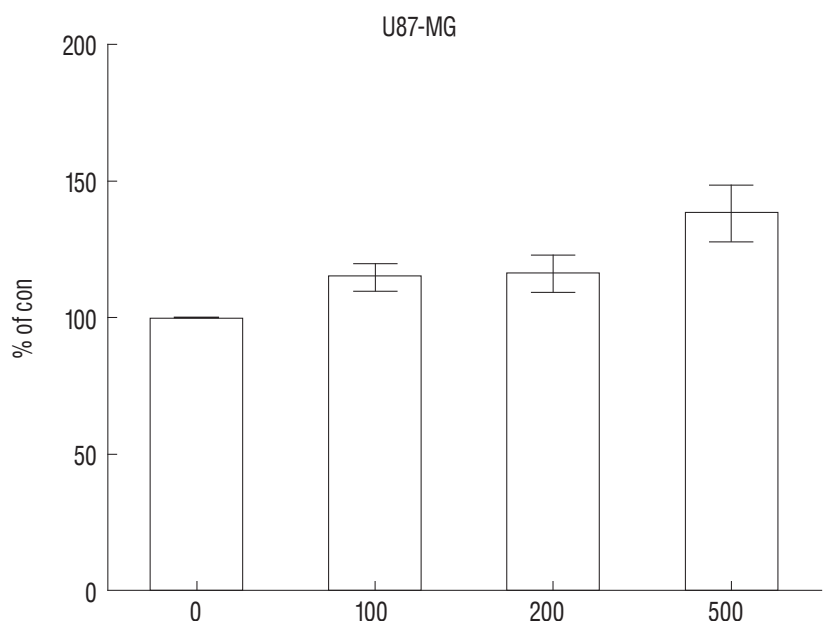

(D)

NGF- $\beta$ (nM)

Fig. 3. Expression of Notch1 in the reverse transcription polymerase chain reaction (RT-PCR) (A) and a dose-dependent effect of nerve growth factor (NGF) on Notch1 expression in the U87-MG cell line $(p=0.044)(B)$; expression of Notch1 in the Western blot analysis (C) and a dose-dependent effect of nerve growth factor (NGF) on Notch1 expression in the U87-MG cell line $(p=0.037)(D)$. GAPDH : glyceraldehyde-3-phosphate dehydrogenase.

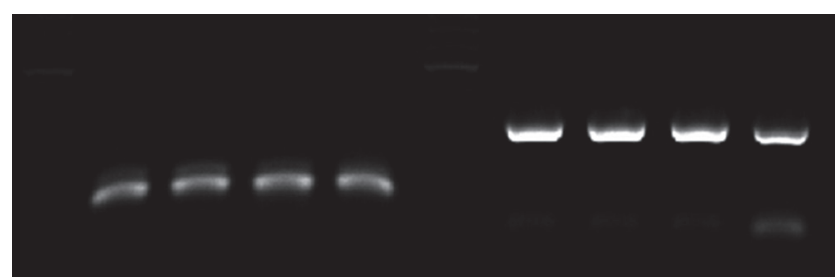

A Hes1

GAPDH

U87-MG

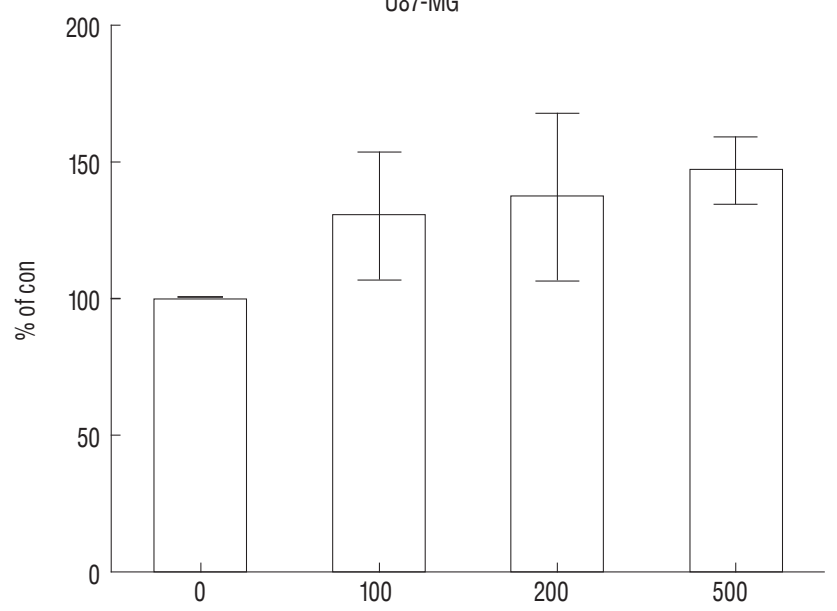

(B)

NGF- $\beta$ (nM)

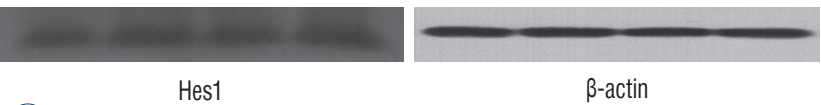

(C)

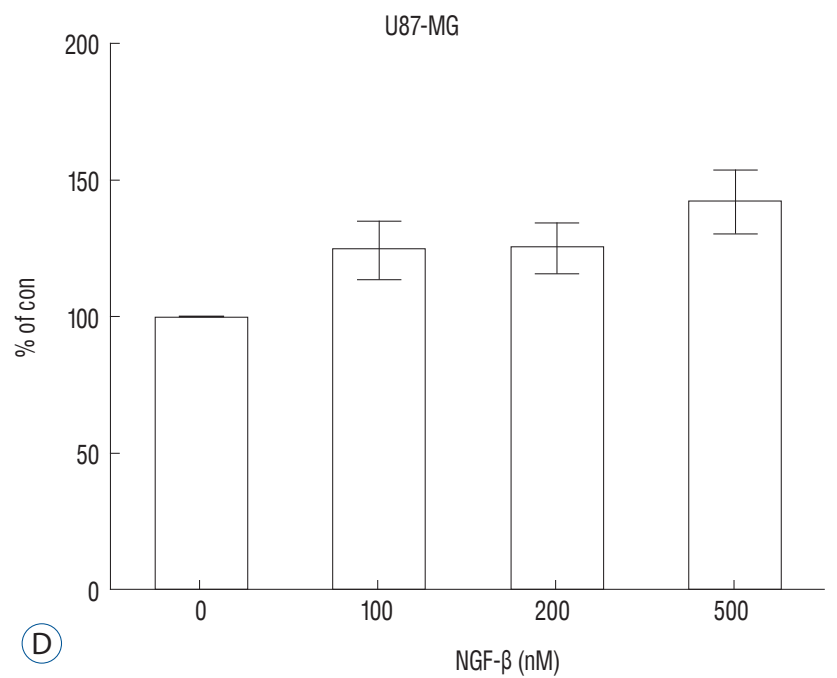

Fig. 4. Expression of Hes1 in the reverse transcription polymerase chain reaction (RT-PCR) (A) and a dose-dependent effect of nerve growth factor (NGF) on Hes1 expression in the U87-MG cell line $(p=0.020)(B)$; Expression of Hes1 in the Western blot analysis $(C)$ and a dose-dependent effect of NGF on Hes1 expression in the U87-MG cell line ( $p=0.037)$ (D). GAPDH : glyceraldehyde3-phosphate dehydrogenase. 
reducing the target was identified through quantitative PCR. Without lipofectamine, the mean values of Notch 1 were 1.239 in controls and 1.262 in $100 \mathrm{nM} \mathrm{NGF-} \beta$ samples ( $p=0.0003)$. In lipofectamine-only, the mean values were 1.201 in control and 1.253 in $100 \mathrm{nM} \mathrm{NGF-} \beta$ ( $p=0.0063)$. In negative controls with Notch1 siRNA, the mean values were 1.195 in control and 1.224 in $100 \mathrm{nM}$ NGF- $\beta$ ( $p=0.0013)$. After transfection with Notchl siRNA, however, there was no significant difference between controls and $100 \mathrm{nM} \mathrm{NGF-} \beta$ (1.181 and 1.180, respectively) ( $p=0.887$ ) (Fig. 5A and B). In the absence of lipofectamine, the mean values of Hes1 were 1.266 in the control and 1.346 in 100 nM NGF- $\beta$ ( $p=0.0005)$. In lipofectamine-only samples, the mean values were 1.092 in the control and 1.201 in $100 \mathrm{nM}$ NGF- $\beta$ ( $p=0.0053$ ). In the negative control of Hesl siRNA, the mean values were 1.044 in the control and 1.135 in $100 \mathrm{nM}$ NGF- $\beta$ ( $p=0.0003)$. After transfection with Hesl siRNA, there was no significant difference between controls and $100 \mathrm{nM}$ NGF- $\beta$ (0.857 and 0.869 , respectively) $(p=0.075)$ (Fig. $5 \mathrm{C}$ and D).
These findings demonstrated that the effects of NGF on U87MG cell line were suppressed by Notch1 siRNA.

\section{DISCUSSION}

Glioblastoma is the most common malignant brain tumor and the prognosis is poor. As knowledge has increased about the molecules involved in glioblastoma formation, various specific target therapies, such as epidermal growth factor, Akt, Hedgehog, mammalian target of rapamycin (mTOR), phosphoinositide 3-kinase, platelet-derived growth factor receptor, Raf, and transforming growth factor $\beta$ (TGF- $\beta$ ) have been introduced $^{16)}$. The studies of the interactions between NGF and Notch signaling in glioblastoma may address the problems related to progress of malignancy and the difficulty of treatment. However, the relationship between Notch1 and NGF in glioblastoma remains unknown. In this study, the relationship

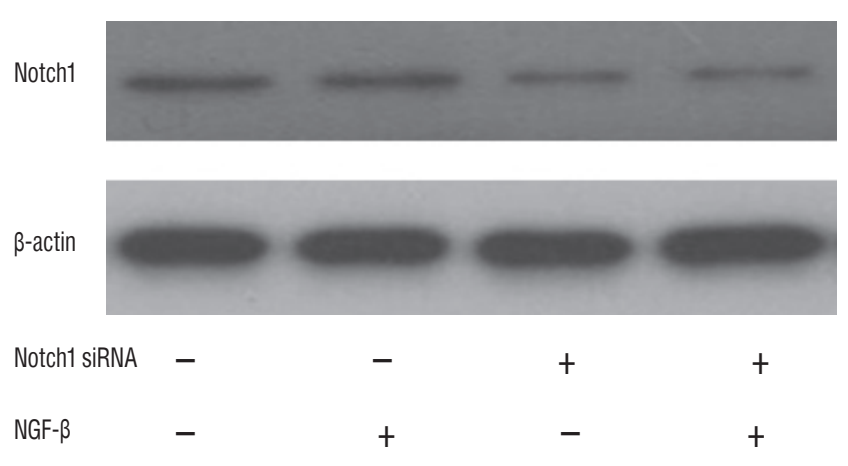

(A)

Hes1

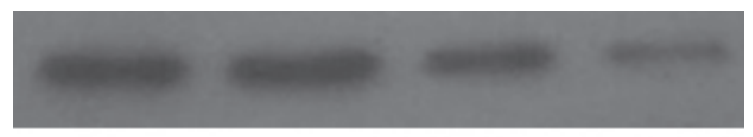

$\beta$-actin

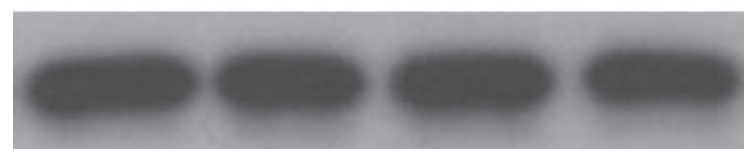

Hes1 siRNA

NGF- $\beta$

(C)

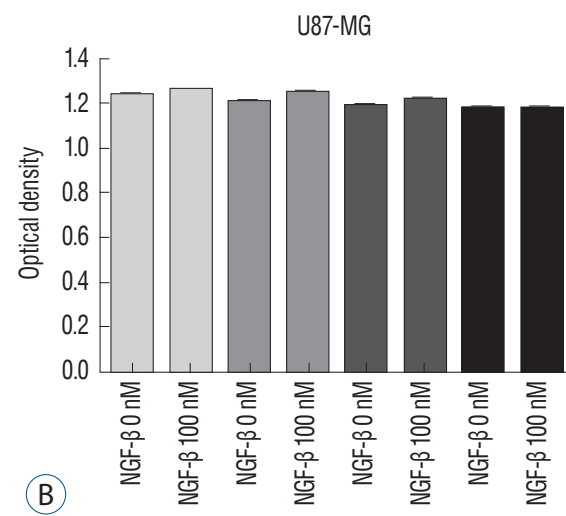

U87-MG

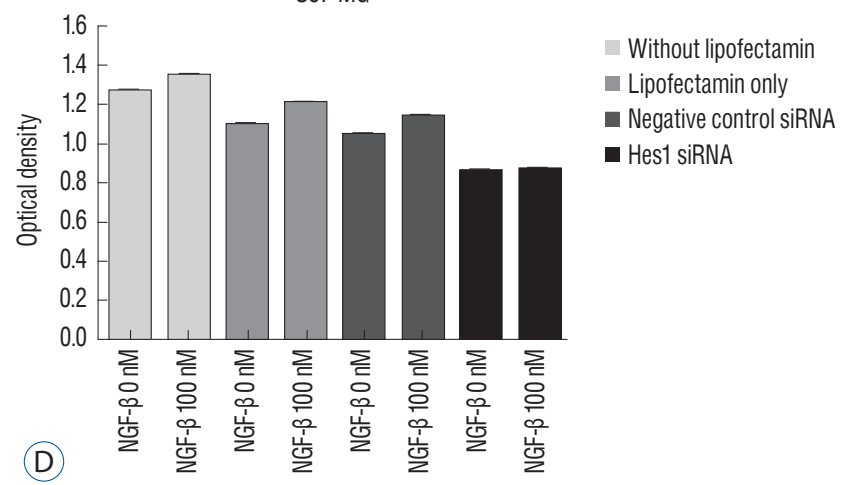

Fig. 5. Expression of Notch1 mall interfering RNA (siRNA) in the Western blot analysis (A). Notch1 siRNA suppresses the effects of nerve growth factor (NGF) on U87-MG cell proliferation. There was difference in without lipofectamin, in lipofectamin only, and in negative control siRNA $(p<0.05)$, but no significant difference in Notch1 siRNA ( $p=0.887$ ) (B). Expression of Hes1 siRNA in the Western blot analysis (C). Hes1 siRNA suppresses the effects of NGF on U87-MG cell proliferation. There was difference in without lipofectamin, in lipofectamin only, and in negative control siRNA $(p<0.05)$, but no significant difference in Hes1 siRNA ( $p=0.075)$ (D). 
between NGF and Notch1 signaling in U87-MG cell lines was evaluated and the results suggest that NGF stimulates glioblastoma proliferation through Notch1 receptor signaling.

Notch signaling has been linked to the pathogenesis of various cancers ${ }^{19)}$. Out of four Notch receptors, Notch1 has been reported to act as oncogenein many tumors, including pancreatic cancer, cervical cancer, renal cell carcinoma, and lymphomas, ovarian cancer and breast cancer ${ }^{13,15,21,29,40)}$. However, it acts as a tumor suppressor in some tumors, such as murine skin tumors and non-small cell lung cancers ${ }^{24,35)}$. Similar characteristics of Notchl have been reported in gliomas. Xu et al. ${ }^{38)}$ reported that the expression of Notch1 showed positive correlation with glioma progression. In another report, high expression of Notchl was shown to be an independent predictor of poor prognosis in glioma ${ }^{20)}$. However, some authors reported an antiproliferative role of Notch1, which means a favorable prognosis with Notch1 expression in glioma ${ }^{8,27,28)}$. These findings mean the action of Notch1 in gliomas and Notch1 signaling could be related to complex factors. A growing body of evidence suggests that Notchl signaling is related to progression in gliomas ${ }^{7200}$. However, the exact mechanism is still unclear.

NGF is a member of the neurotrophin family, which includes brain-derived neurotrophic factor, neurotrophin 3 , and neurotrophin $4 / 5$, and it plays a critical role in cell growth and differentiation in both the peripheral and central nervous system ${ }^{37}$. NGF interacts with both the high affinity TrkA, and the common neurotrophin $\mathrm{p} 75^{\mathrm{NTR}}$ receptors ${ }^{6}$. These receptors and NGF are produced during development, adult life, and aging of cells in various tissues such as the CNS, PNS, immune and inflammatory systems ${ }^{34)}$. Recently, these two receptors have been identified in human glioblastoma cell lines (U87, U251, and U373) and there are several reports suggesting that glioblastoma growth could be enhanced by $\mathrm{NGF}^{10,18,25,33)}$. Singer et al. ${ }^{33)}$, reported that glioblastoma growth can be induced by NGF acting by Trk A receptor phosphorylation. The exact role of Trk receptor in glioblastoma is, however, still unknown.

We found that Notchl expression was higher in glioblastoma tissue than in the adjacent or in normal brain tissue. Next, we evaluated the effect of NGF- $\beta$ in U87-MG cell lines by MTT assay and showed that NGF stimulates U87-MG cell lines dosedependently. A similar finding was observed in previous reports. Oelmann et al. ${ }^{25)}$ reported that growth stimulation by NGF was dose-dependent in U87-MG but not significant in 87HG-31. In another report, NGF exhibited promigratory and proliferatory activities in human glioma cell lines (LN229) .

To determine whether this proliferation by NGF was associated with Notch1 signal pathway, we evaluated the Notch1 and Hesl expression and showed that Notch1 and Hesl expression were increased by NGF dose-dependently. This results means NGF is related to up-regulation of Notch1 pathway in glioblastomas. Although there are no reports showing the exact relationship between the NGF and Notch1 pathway in glioblastomas, there are some reports suggesting NGF is related to the regulation of Notchl pathway. Faux et al.") reported that growth factors such as fibroblast growth factorl (FGF1) and FGF2 increased Notch1 expression and inhibited the neuronal differentiation of the neuroepithelial precursor (NEP) cells. However, some authors reported that NGF induced Notch1 downregulation in other cell types ${ }^{14,36)}$. Subsequently, to confirm the NGF effect on the Notch1 signaling, siRNA was used to target Notch1 in this study. Compared to before transfection with Notch1 siRNA, there was no significant difference in U87-MG cell proliferation after transfection with Notch1 siRNA. This suggests that the NGF effect on U87-MG cell proliferation was suppressed by Notch1 siRNA, and that NGF might induce upregulation of Notch1 receptor.

A recent study showed that Notchl and Hesl were also components of the NGF pathway. In an acute retinal injury model, Jian et al. ${ }^{14)}$ reported that transient Notch1 down-regulation and NGF up-regulation promoted de-differentiated Muller cells to differentiate into photoreceptors. Ström et al. ${ }^{36)}$ observed that endogenous Hes1 was related to the NGF pathway and that DNA binding of Hes1 was post-translationally inhibited during NGF signaling in PC12 cell lines. They also suggested that this posttranslational effect on Hesl was conducted by the phosphorylation of the protein kinase C site on its DNA binding domain. In our study, however, NGF induced up-regulation Notch1 signaling and cell proliferation. The reason why our findings are not consistent with previous reports are as follows : 1) Notch1 signaling could be different depending on cell type and in each cell line, 2) decreased activity of kinases that phosphorylate Hesl, or increased activity of a phosphatase during NGF signaling in glioblastomas, and 3) the complexity of Notch1 function through other Notch family members or ligands. Which of these effects contributes to the response remains for future study. The reason for the inhibitory effect of Notchl siRNA on cell proliferation in this study seems not so dramatic compared to the effect of hes1 siRNA may be as follows : 1) There may be 
more linkages between the Notch1 receptor and Hes1, 2) Second, inhibition of Hesl may be more effective in blocking the effect of NGF in glioblastoma, and 3) The effect of hes1 inhibition in this cell may be more specific to glioblastoma cell proliferation.

Some limitations could be considered in this study. 1) To identify for the relationship between NGF and Notch signaling, different kinds of glioblastoma cell lines are needed, 2) Although the results showed the NGF effect on the Notch signaling in glioblastoma, more molecular works looks necessary including r-secretase inhibition, Notch1 intracellular domain, other Hes families, and DNA binding proteins, 3) IHC staining showed clear positivity, but used the number of samples was too small, and 4) We did not study the downstream pathway of the NGF receptor including tyrosine kinases. It will be done in the next study.

\section{CONCLUSION}

This study suggests that NGF stimulates glioblastoma cell proliferation in a dose-dependent manner through the Notch1 receptor, and that NGF also induces up-regulation of Notch1 signaling. These findings suggest that targeting NGF or Notch1 could be a therapeutic option for glioblastoma patients.

\section{CONFLICTS OF INTEREST}

No potential conflict of interest relevant to this article was reported.

\section{INFORMED CONSENT}

Informed consent was obtained from all individual participants included in this study.

\section{References}

1. Artavanis-Tsakonas $S$, Rand MD, Lake RJ : Notch signaling: cell fate control and signal integration in development. Science 284 : 770-776, 1999
2. Aster JC, Pear WS : Notch signaling in leukemia. Curr Opin Hematol 8 : 237-244, 2001

3. Bigas $A$, Martin DI, Milner $L A$ : Notch1 and Notch2 inhibit myeloid differentiation in response to different cytokines. Mol Cell Biol 18 : 23242333, 1998

4. Bolós V, Grego-Bessa J, de la Pompa JL : Notch signaling in development and cancer. Endocr Rev 28 : 339-363, 2007

5. Brown MC, Staniszewska I, Lazarovici P, Tuszynski GP, Del Valle L, Marcinkiewicz $C$ : Regulatory effect of nerve growth factor in alpha9beta1 integrin-dependent progression of glioblastoma. Neuro Oncol 10 : 968-980, 2008

6. Chao MV, Hempstead BL : p75 and Trk: a two-receptor system. Trends Neurosci $18: 321-326,1995$

7. Chen J, Kesari S, Rooney C, Strack PR, Chen J, Shen H, et al. : Inhibition of Notch signaling blocks growth of glioblastoma cell lines and tumor neurospheres. Genes Cancer $1: 822-835,2010$

8. Cheung HC, Corley LJ, Fuller GN, McCutcheon IE, Cote GJ : Polypyrimidine tract binding protein and notch1 are independently re-expressed in glioma. Mod Pathol 19 : 1034-1041, 2006

9. Faux CH, Turnley AM, Epa R, Cappai R, Bartlett PF : Interactions between fibroblast growth factors and notch regulate neuronal differentiation. J Neurosci 21 : 5587-5596, 2001

10. Giraud S, Loum E, Bessette B, Mathonnet M, Lalloué $F$ : P75 neurotrophin receptor is sequestered in the Golgi apparatus of the U-87 MG human glioblastoma cell line. Int J Oncol 38 : 391-399, 2011

11. Goretzki PE, Wahl RA, Becker R, Koller C, Branscheid D, Grussendorf M, et al. : Nerve growth factor (NGF) sensitizes human medullary thyroid carcinoma (hMTC) cells for cytostatic therapy in vitro. Surgery 102 : 1035-1042, 1987

12. Greenwald I : LIN-12/Notch signaling: lessons from worms and flies. Genes Dev 12 : 1751-1762, 1998

13. Jang MS, Zlobin A, Kast WM, Miele $L$ : Notch signaling as a target in multimodality cancer therapy. Curr Opin Mol Ther $2:$ 55-65, 2000

14. Jian Q, Tao Z, Li Y, Yin ZQ : Acute retinal injury and the relationship between nerve growth factor, notch1 transcription and short-lived dedifferentiation transient changes of mammalian Müller cells. Vision Res 110(Pt A) : 107-117, 2015

15. Jundt F, Anagnostopoulos I, Förster R, Mathas S, Stein H, Dörken B : ACtivated Notch1 signaling promotes tumor cell proliferation and survival in Hodgkin and anaplastic large cell lymphoma. Blood 99 : 3398-3403, 2002

16. Kanu 00, Mehta A, Di C, Lin N, Bortoff K, Bigner DD, et al. : Glioblastoma multiforme: a review of therapeutic targets. Expert Opin Ther Targets $13: 701-718,2009$

17. Kopan $\mathrm{R}$, llagan $M X$ : The canonical notch signaling pathway: unfolding the activation mechanism. Cell $137: 216-233,2009$

18. Lawn S, Krishna N, Pisklakova A, Qu X, Fenstermacher DA, Fournier M, et al. : Neurotrophin signaling via TrkB and TrkC receptors promotes the growth of brain tumor-initiating cells. J Biol Chem 290 : 3814-3824, 2015

19. Leong KG, Karsan $A$ : Recent insights into the role of Notch signaling in 
tumorigenesis. Blood 107 : 2223-2233, 2006

20. Li J, Cui $Y$, Gao G, Zhao Z, Zhang $H$, Wang $X$ : Notch1 is an independent prognostic factor for patients with glioma. J Surg Oncol 103 : 813-817, 2011

21. Liu Y, Su C, Shan Y, Yang S, Ma G : Targeting notch1 inhibits invasion and angiogenesis of human breast cancer cells via inhibition nuclear factorkappaB signaling. Am J TransI Res 8 : 2681-2692, eCollection 2016

22. Miele L, Golde T, Osborne B : Notch signaling in cancer. Curr Mol Med $6:$ : 905-918, 2006

23. Miele L, Miao H, Nickoloff BJ : Notch signaling as a novel cancer therapeutic target. Curr Cancer Drug Targets 6 : 313-323, 2006

24. Nicolas $M$, Wolfer $A$, Raj $K$, Kummer JA, Mill $P$, van Noort $M$, et al. : Notch1 functions as a tumor suppressor in mouse skin. Nat Genet 33 : 416-421, 2003

25. Oelmann E, Sreter L, Schuller I, Serve H, Koenigsmann M, Wiedenmann B, et al. : Nerve growth factor stimulates clonal growth of human lung cancer cell lines and a human glioblastoma cell line expressing high-affinity nerve growth factor binding sites involving tyrosine kinase signaling. Cancer Res 55 : 2212-2219, 1995

26. Park YH, Kim SJ, Jeong BH, Herzog TJ, Wright J, Kitajewski J, et al. : Follicular stimulating hormone enhances Notch 1 expression in SK-OV-3 ovarian cancer cells. J Gynecol Oncol 21 : 119-124, 2010

27. Phillips HS, Kharbanda S, Chen R, Forrest WF, Soriano RH, Wu TD, et al. : Molecular subclasses of high-grade glioma predict prognosis, delineate a pattern of disease progression, and resemble stages in neurogenesis. Cancer Cell 9 : 157-173, 2006

28. Purow BW, Haque RM, Noel MW, Su Q, Burdick MJ, Lee J, et al. : Expression of Notch-1 and its ligands, Delta-like-1 and Jagged-1, is critical for glioma cell survival and proliferation. Cancer Res 65 : 2353-2363, 2005

29. Qian XQ, Chen LL, Cheng Q, Tian Y, Luo XF, Wan XY : Inhibition of Notch 1 receptor influenced the differentiation of Lin-CD45RA-dendritic cell precursors within ovarian carcinoma microenvironment. BMC Immunol $17: 14,2016$
30. Rakowicz-Szulczyńska EM, Herlyn M, Koprowski H : Nerve growth factor receptors in chromatin of melanoma cells, proliferating melanocytes, and colorectal carcinoma cells in vitro. Cancer Res 48(24 Pt 1) : 7200-7206, 1988

31. Rakowicz-Szulczynska EM, Reddy U, Vorbrodt A, Herlyn D, Koprowski $\mathrm{H}$ : Chromatin and cell surface receptors mediate melanoma cell growth response to nerve growth factor. Mol Carcinog 4 : 388-396, 1991

32. Revoltella RP, Butler RH : Nerve growth factor may stimulate either division or differentiation of cloned C1300 neuroblastoma cells in serumfree cultures. J Cell Physiol 104 : 27-33, 1980

33. Singer HS, Hansen B, Martinie D, Karp CL : Mitogenesis in glioblastoma multiforme cell lines: a role for NGF and its TrkA receptors. J Neurooncol 45 : 1-8, 1999

34. Sofroniew MV, Howe CL, Mobley WC : Nerve growth factor signaling, neuroprotection, and neural repair. Annu Rev Neurosci 24 : 12171281, 2001

35. Sriuranpong V, Borges MW, Ravi RK, Arnold DR, Nelkin BD, Baylin SB, et al. : Notch signaling induces cell cycle arrest in small cell lung cancer cells. Cancer Res 61 : 3200-3205, 2001

36. Ström A, Castella P, Rockwood J, Wagner J, Caudy M : Mediation of NGF signaling by post-translational inhibition of HES-1, a basic helix-loophelix repressor of neuronal differentiation. Genes Dev 11 : 3168-3181, 1997

37. Takei Y, Laskey R : Interpreting crosstalk between TNF-alpha and NGF: potential implications for disease. Trends Mol Med 14 : 381-388, 2008

38. Xu P, Yu S, Jiang R, Kang C, Wang G, Jiang H, et al. : Differential expression of Notch family members in astrocytomas and medulloblastomas. Pathol Oncol Res 15 : 703-710, 2009

39. Yavropoulou MP, Maladaki A, Yovos JG : The role of Notch and Hedgehog signaling pathways in pituitary development and pathogenesis of pituitary adenomas. Hormones (Athens) $14:$ 5-18, 2015

40. Zlobin A, Jang M, Miele $L$ : Toward the rational design of cell fate modifiers: Notch signaling as a target for novel biopharmaceuticals. Curr Pharm Biotechnol 1 : 83-106, 2000 